\title{
Test Re-test Reliability of Single and Multijoint Strength Properties in Female Australian Footballers
}

\author{
Daniel Kadlec ${ }^{\text {}^{*}}$ (D), Matthew J. Jordan², Leanne Snyder ${ }^{1}$, Jacqueline Alderson ${ }^{3,4}$ and Sophia Nimphius ${ }^{1,4}$
}

\begin{abstract}
Purpose: To examine the test re-test reliability of isometric maximal voluntary contractions (MVC) of hip adduction $\left(\mathrm{ADD}_{\mathrm{ISO}}\right)$, hip abduction $\left(\mathrm{ABD}_{\mathrm{ISO}}\right)$, and multijoint leg extension (SQUAT ${ }_{\mathrm{ISO}}$ ) in sub-elite female Australian footballers.

Methods: Data were collected from 24 sub-elite female Australian footballers (age $22.6 \pm 4.5$ years; height $169.4 \pm$ $5.5 \mathrm{~cm}$; body mass $66.6 \pm 8.0 \mathrm{~kg} ; 4.5 \pm 4.4$ years sport-specific training; $2.5 \pm 2.0$ years unstructured resistance training) from the same club on two non-consecutive days. Participants performed three isometric MVCs of ADD ISO, $_{\text {, }}$ $\mathrm{ABD}_{\text {ISO, }}$, and SQUAT ${ }_{I S O}$. The SQUAT 1 ISO was performed at $140^{\circ}$ knee flexion with a vertical trunk position and $\mathrm{ADD}_{\text {ISO }}$ and $A B D_{150}$ measures were performed in a supine position at $60^{\circ}$ of knee flexion and $60^{\circ}$ hip flexion. Reliability was assessed using paired $t$ tests and the intraclass correlation coefficient (ICC) with 95\% confidence intervals (Cl), typical error (TE), and coefficient of variation (CV\%) with 95\% Cl.

Results: SQUAT Iso peak force (ICC .95; CV\% 4.1), ABD IsO for left, right, and sum (ICC .90-.92; CV\% 5.0-5.7), and ADD Iso for left, right, and sum (ICC .86-.91; CV\% 6.2-6.9) were deemed acceptably reliable based on predetermined criteria (ICC $\geq .8$ and CV\% $\leq 10)$.

Conclusion: SQUAT ISO, $\mathrm{ABD}_{\mathrm{ISO}}$, and $\mathrm{ADD}_{\mathrm{ISO}}$ tests demonstrated acceptable reliability for the assessment of peak force in sub-elite female Australian footballers, suggesting these assessments are suitable for muscle strength testing and monitoring adaptations to training.
\end{abstract}

\section{Key Points}

- Hip abduction, hip adduction and multijoint isometric strength testing demonstrated high testretest reliability in sub-elite female athletes with limited structured resistance training experience.

- The assessments examined in the current study may be a valuable component of athlete monitoring for readiness and fatigue and as a component of a comprehensive test battery for assessing injury risk

- The results from the current study can contribute to the development of normative data for isometric

\footnotetext{
* Correspondence: d.kadlec@ecu.edu.au

${ }^{1}$ School of Medical and Health Sciences, Edith Cowan University, 270

Joondalup Drive, Joondalup, WA 6027, Australia

Full list of author information is available at the end of the article
}

$\mathrm{ADD}_{\text {ISO }}, \mathrm{ABD}_{\text {ISO }}$, and SQUAT $\mathrm{ISO}_{\text {ISO }}$ strength in subelite female athletes.

\section{Introduction}

Lower limb maximal muscle strength is important for athletic performance and injury prevention [1] and is often assessed and monitored in an athletic population [2]. Multijoint isometric strength testing such as the isometric mid-thigh pull or isometric squat (SQUAT ${ }_{\text {ISO }}$ ) demonstrate good test-retest reliability and may involve a lower injury risk compared with repetition maximum (RM) strength testing using free weights. The reliability of multijoint isometric strength testing has been investigated in elite female athletes who are experienced with strength training [3]; however, studies investigating the reliability of SQUAT ${ }_{\text {ISO }}$ with sub-elite female athletes 
Table 1 Test re-test reliability of the isometric squat, abduction and adduction maximal force. Session scores expressed as mean (SD)

\begin{tabular}{|c|c|c|c|c|c|c|}
\hline & Day 1 & Day 2 & $p$ & $\mathrm{ICC}_{3,1}[95 \% \mathrm{Cl}]$ & TE & $\mathrm{CV} \%[95 \% \mathrm{Cl}]$ \\
\hline SQUAT ISO $_{\text {(N) }}$ & 2127 (393) & $2099(401)$ & .30 & $.95[.88-.98]$ & 91 & $4.1[3.2-5.8]$ \\
\hline ADD Iso sum (N) & $651(108)$ & $650(112)$ & .90 & $.90[.78-.95]$ & 36 & 6.4 [4.9-9.0] \\
\hline $\mathrm{ADD}_{\text {ISO }}$ left $(\mathrm{N})$ & $323(52)$ & $319(51)$ & .39 & $.86[.70-.94]$ & 19 & 6.9 [5.4-9.9] \\
\hline $\mathrm{ADD}_{\text {ISO }}$ right $(\mathrm{N})$ & $327(58)$ & $330(62)$ & .48 & $.91[.81-.90]$ & 18 & $6.2[4.8-8.8]$ \\
\hline $\mathrm{ABD}_{\text {Iso }} \operatorname{sum}(\mathrm{N})$ & $598(110)$ & $599(102)$ & .87 & $.92[.83-.97]$ & 30 & $5.0[3.9-7.1]$ \\
\hline $\mathrm{ABD}_{\text {ISO }}$ left $(\mathrm{N})$ & $310(53)$ & $313(51)$ & .49 & .90 [.79-96] & 17 & $5.5[4.2-7.7]$ \\
\hline $\mathrm{ABD}_{\text {Iso }}$ right $(\mathrm{N})$ & 287 (59) & $285(52)$ & .70 & $.91[.80-96]$ & 17 & $5.7[4.4-8.1]$ \\
\hline
\end{tabular}

SQUAT ISO isometric squat, $A D D_{I S O}$ adduction, $A B D_{I S O}$ abduction, summated left and right ADD and ABD are represented by "sum", $I C C_{3,1}$ intraclass-correlation coefficient, 95\% Cl 95\% confidence interval, TE typical error, CV coefficient of variation. Significance set at $p<.05$

with limited structured resistance training experience are lacking. Further, while multijoint testing has been shown to be reliable, it is possible that gross motor strategy used during multijoint testing may lack sensitivity to identifying isolated fatigue [4] and therefore it may be useful to further evaluate the reliability of multijoint and single-joint assessments within the same cohort.

In addition to multijoint isometric strength testing, single joint isometric strength assessments are often used in athletic populations to assess lower limb maximal strength due to the relationship between isolated joint strength, lower limb injuries, and performance. For example, athletes with groin pain have been shown to demonstrate lower hip adduction ( $\mathrm{ADD}_{\mathrm{ISO}}$ ) maximal strength compared to healthy athletes [5]. Also, a positive association has been demonstrated between decreased hip abduction $\left(\mathrm{ABD}_{\mathrm{ISO}}\right)$ strength and lower limb movement mechanics associated with injury [6] alongside an increased generalized risk for knee injury [7]. However, $\mathrm{ABD}_{\mathrm{ISO}}$ and $\mathrm{ADD}_{\mathrm{ISO}}$ strength testing reliability has not been reported in sub-elite female Australian football. The importance of reliable hip strength measurement to assist in identification of lower limb injury risk is of clear importance considering the known priority to consider risk of ligamentous knee injuries in this population $[8,9]$.

The purpose of this study was to examine the testretest reliability of isometric maximum voluntary contractions (MVCs) of $\mathrm{ADD}_{\mathrm{ISO}}, \mathrm{ABD}_{\mathrm{ISO}}$, and SQUAT $\mathrm{TSO}_{\mathrm{ISO}}$ in sub-elite trained female Australian footballers. We hypothesized that the test-retest reliability conducted with sub-elite trained female athletes would be acceptable and comparable to that reported for elite athletes.

\section{Methods}

\section{Participants}

Female sub-elite Australian footballers $(n=24$; age 22.6 \pm 4.5 years; height $169.4 \pm 5.5 \mathrm{~cm}$; weight $66.6 \pm 8.0$; 4.5 \pm 4.4 years sport-specific training; $2.5 \pm 2.0$ years resistance training) were recruited from a single club from two competition grades-West Australian Football League Women (WAFLW) and WAFLW Reserves squad. Participants indicated they had no previous history of engaging in supervised structured resistance training program despite reported resistance training of free/unstructured resistance training. All participants provided written informed consent prior to testing (University Research Ethics Approval \#22459). Isometric MVCs were obtained from two non-consecutive testing sessions separated by $48 \mathrm{~h}$. Participants performed a standardized warm up prior to the isometric MVCs consisting of five bodyweight squats, five backwards lunges per side, and five submaximal countermovement jumps. The testing sessions were supervised by the same qualified exercise testing practitioner who instructed the participants to push as "fast and as hard as possible" and provided strong verbal encouragement throughout the test.

\section{Isometric Squat}

Participants performed the SQUAT ${ }_{\text {ISO }}$ against a fixed barbell in a squat rack at a joint angle of $140^{\circ}$ knee flexion while maintaining an upright trunk position determined using a hand-held goniometer. Foot-width was measured and remained consistent between trials and testing days. Participants then performed warm-up contractions including a 5-s submaximal contraction with $50 \%$ effort followed by a 3-s contraction at $70-80 \%$ effort prior to performing the isometric MVCs. Participants completed three 5-s isometric MVCs separated by a 2-min rest period [10]. The vertical ground reaction force was obtained from each limb using a dual force plate system (PASPO Force Platform PS-2141, PASCO, Roseville, USA) that sampled at $1000 \mathrm{~Hz}$. The trial with the highest maximum force was used in the statistical analysis.

\section{Isometric Hip Strength}

Participants were positioned beneath a Force Frame Strength Testing System (Vald Performance, Albion, Australia) in a supine position with $60^{\circ}$ of knee flexion and the feet placed flat on the ground. The femoral 

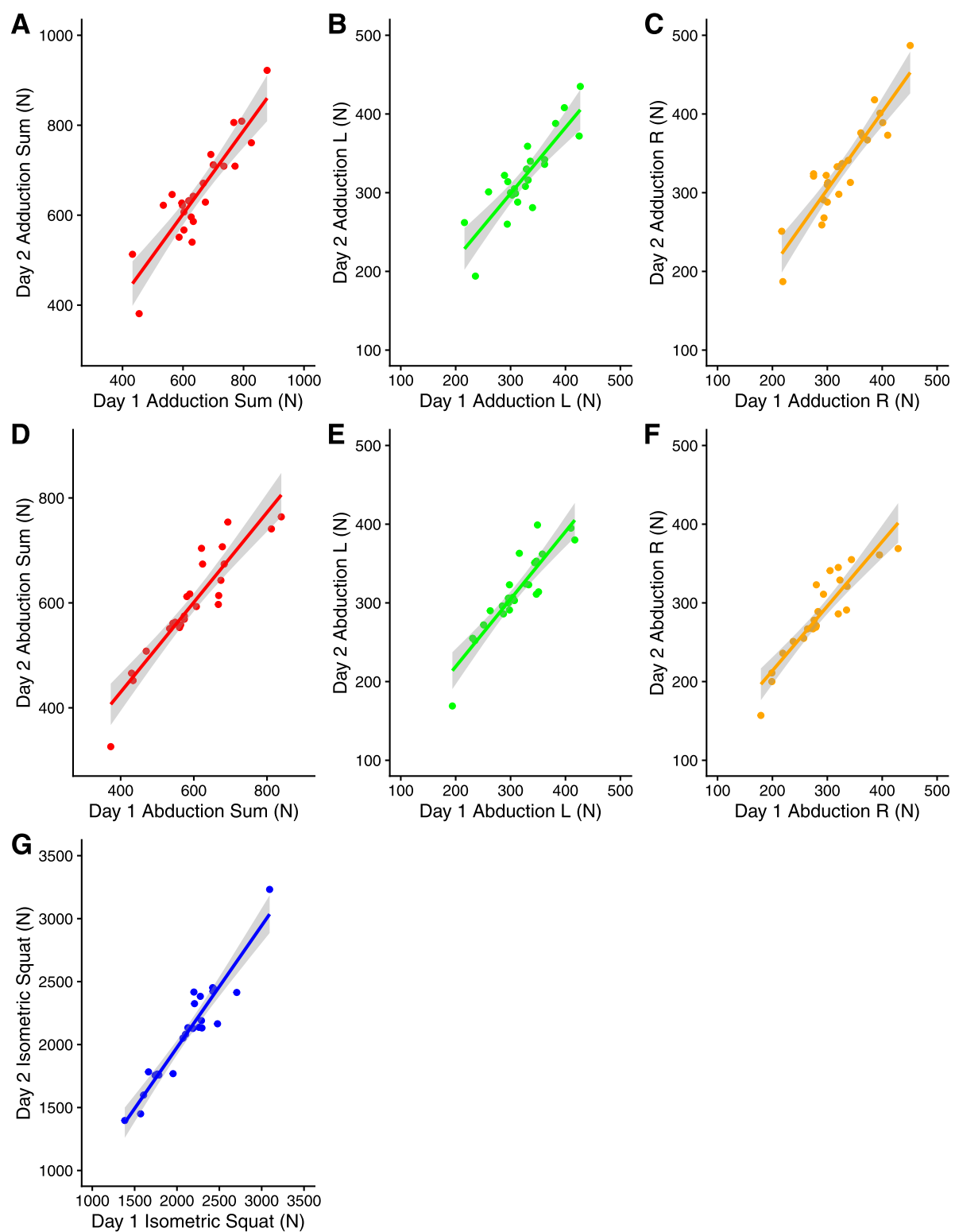

Fig. 1 Test re-test data visualized for each isometric assessment. a Adduction sum of left and right. b Left adduction. c Right adduction. d Abduction summed from left and right. e Left abduction. $\mathbf{f}$ Right adduction. $\mathbf{g}$ Isometric squat. Data is presented with a linear fit and $95 \%$ confidence cloud for visual observation of all data points

condyles were positioned in the center of the dynamometer and force was recorded from each limb simultaneously using load cells sampling at $50 \mathrm{~Hz}$. Participants performed a 5 -s submaximal contraction with $50 \%$ effort followed by a 3 -s contraction at 70 $80 \%$ effort prior to performing the isometric MVCs. Participants then completed three 5-s isometric MVCs of $A B D_{\text {ISO }}$ and $A D D_{\text {ISO }}$ separated by a 30 -s rest period. The maximum left and right isometric force and maximum total isometric force (sum of left and right) were obtained, and the trial with the maximum total force was used for analysis.

\section{Statistical Analysis}

Mean, standard deviation (SD), and 95\% confidence intervals $[\mathrm{CI}]$ were calculated for each variable. Paired samples $t$ test with significance set at $p<.05$ and intraclass correlation coefficient 3,1 (ICC) were calculated in R ( $\mathrm{R}$ Core Team 2018, http://www.R-project.org/; see supplemental code for packages). In addition, typical error (TE) and coefficient of variation $(\mathrm{CV})$ of the log-transformed data with 95\% CI was calculated by published formula (https://www. sportsci.org/resource/stats/xrely.xls). Acceptable reliability was established by predetermined criteria of an ICC $\geq .8$ 
and $\mathrm{CV} \leq 10 \%$ based on interpretation of previous recommendations [11].

\section{Results}

No significant differences between testing session one and testing session two were observed for $\mathrm{SQUAT}_{\mathrm{ISO}}$ or $A D D_{\text {ISO }}$ and $A B D_{\text {ISO }}$ for left, right, or sum (Table 1) supportive of absolute reliability. All isometric tests assessed demonstrated acceptable relative reliability as detailed in Table 1 with the range for ICC of $.86-.95$ and $\mathrm{CV} \%$ of 4.1-6.9. Data appeared normally distributed and followed a linear pattern (Fig. 1) supporting assessment of relative and absolute reliability assessments reported in Table 1.

\section{Discussion}

Consistent with previous research and with the study hypothesis, $\mathrm{ADD}_{\mathrm{ISO}}, \mathrm{ABD}_{\mathrm{ISO}}$, and $\mathrm{SQUAT}_{\mathrm{ISO}}$ testing demonstrated high test-retest reliability in a sub-elite female athlete population (Table 1; Fig. 1). The test-retest reli-

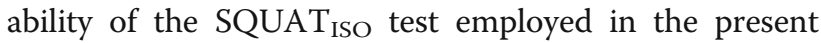
study (ICC .95 [.88-.98]; CV\% 4.1 [3.2-5.8]), was similar to that reported in male and female elite athletes (ICC .97 [.94-.99]; CV\% 4.6) [3], evidencing the utility of the SQUAT $_{\text {ISO }}$ test for monitoring lower limb maximal muscle strength in sub-elite female athletes. Absolute SQUAT $_{\text {ISO }}$ strength in the current study (day $12127 \pm$ $393 \mathrm{~N}$; day $22099 \pm 401 \mathrm{~N}$ ) were similar to previously reported strength female athletes with at least 6 months of resistance training experience $(2090 \pm 578 \mathrm{~N})$ [3]. The combined results provide support for normative strength values for female athletes and can help practitioners establish standards and identify strength deficits. Consistent with this finding, the reliability of the $\mathrm{ABD}_{\mathrm{ISO}}$ found in the present study (sum $A B D_{\text {ISO }}$ ICC .90; CV\% 6.4) was comparable to the reliability measures reported in a cohort of professional male Australian footballers using the same testing device $\left(\mathrm{ABD}_{\mathrm{ISO}}\right.$ : ICC .94; $\mathrm{CV} \%$ 6.3) [10]. Further, higher reliability was found for the $\mathrm{ADD}_{\text {ISO }}$ and $\mathrm{ABD}_{\text {ISO }}$ tests (ICC .86-.92; CV\% 5.0-6.9) used in this investigation compared with adduction strength assessed using a sphygmomanometer (ICC .86; CV\% 7.6) [12] and isometric hip abduction strength assessment using a hand-held dynamometer (ICC .81-.84) [13].

The present findings are relevant to sport science, sport medicine, and sport performance practitioners as lower body maximal muscle strength including hip abduction and adduction strength are important for performance and injury risk identification in female athletes [1]. Importantly, the testing sessions conducted here were not preceded by familiarization trials and measurements were obtained from female athletes with minimal resistance training experience. As injuries associated with lower limb strength imbalances affect elite and subelite athletes alike, reliable measures of multijoint and single joint muscle strength are essential $[5,8]$. In addition to evaluating lower limb muscle strength for injury risk purposes, the reliability of the methods assessed in this study suggest that these testing methods are well suited for routine athlete monitoring practices aimed at examining changes in lower body muscle strength.

\section{Conclusion}

Consistent with the hypothesis, the present investigation demonstrated high reliability for $\mathrm{ABD}_{\mathrm{ISO}}, \mathrm{ADD}_{\mathrm{ISO}}$, and SQUAT $_{\text {ISO }}$ testing in sub-elite trained female Australian rules footballers with limited resistance training experience. The results from the current study can contribute to the development of normative data for isometric $\mathrm{ADD}_{\mathrm{ISO}}, \mathrm{ABD}_{\mathrm{ISO}}$, and $\mathrm{SQUAT} \mathrm{T}_{\mathrm{ISO}}$ strength in sub-elite female athletes. Therefore, the assessments examined in the current study may be a valuable component of athlete monitoring for readiness and fatigue and as a component of a comprehensive test battery for assessing injury risk.

\section{Additional Files}

Additional file 1:. Supplementary Data. De-identified data for test retest of all participants.

Additional file 2:. Analysis Code. R Script for data analysis.

\section{Abbreviations}

$\mathrm{ABD}_{\text {ISO: }}$ Isometric hip abduction; $\mathrm{ADD}_{\mathrm{ISO}}$ : Isometric hip adduction; ACL: Anterior cruciate ligament; Cl: Confidence intervals; CV\%: Coefficient of variation; ICC: Intraclass correlation coefficient; MVC: Maximal voluntary

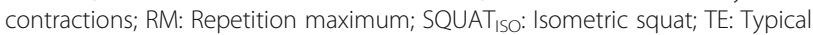
error

\section{Acknowledgements}

$\mathrm{SN}$ is a member of the Australian Centre for Research into Injury in Sport and its Prevention (ACRISP) at Edith Cowan University. ACRISP is one of the International Research Centres for the Prevention of Injury and Protection of Athlete Health supported by the International Olympic Committee (IOC).

\section{Authors' Contributions}

DK, LS, and SN designed the study. DK and LS recruited and managed data collection. DK and SN conducted the analysis. All authors contributed to the manuscript and interpretation of the results. All authors read and approved the final manuscript.

\section{Funding}

Author DK and the project are supported by an Industry Engagement Doctoral Grant with Edith Cowan University and VALD Performance. VALD Performance had no role in study design, data collection, analysis, or interpretation.

\section{Availability of Data and Materials}

All data generated or analyzed during this study are included in this published article [and its supplementary information files].

Ethics Approval and Consent to Participate

All procedures performed in the studies involving human participants were in accordance with the ethical standards of Edith Cowan University's Ethical Advisory Panel (University Research Ethics Approval \#22459). The study 
conforms to and was conducted in accordance with the 1964 Helsinki Declaration and its later amendments, and comparable ethical standards.

\section{Consent for Publication}

Not applicable

\section{Competing Interests}

Author DK is supported by an Industry PhD Industry Engagement Doctoral Grant with Edith Cowan University and VALD Performance which includes provision of the Force Frame Strength Testing System as described in the funding statement. The remaining authors Matthew J. Jordan, Leanne Snyder, Jacqueline Alderson and Sophia Nimphius have no competing interests to declare.

\section{Author details}

${ }^{1}$ School of Medical and Health Sciences, Edith Cowan University, 270 Joondalup Drive, Joondalup, WA 6027, Australia. ${ }^{2}$ Canadian Sport Institute Calgary, ABDISO, Calgary T2N 1N4, Canada. ${ }^{3}$ School of Human Sciences, The University of Western Australia, Perth, Australia. ${ }^{4}$ Sports Performance Research Institute New Zealand (SPRINZ), Auckland University of Technology,

Auckland, New Zealand.

Received: 19 May 2020 Accepted: 15 December 2020

Published online: 09 January 2021

\section{References}

1. Suchomel TJ, Nimphius S, Stone MH. The importance of muscular strength in athletic performance. Sports Med. 2016;46(10):1419-49. https://doi.org/10. 1007/s40279-016-0486-0.

2. Drake D, Kennedy R, Wallace $\mathrm{E}$. The validity and responsiveness of isometric lower body multi-joint tests of muscular strength: a systematic review. Sports Med Open. 2017;3(1):23. https://doi.org/10.1186/s40798-017-0091-2.

3. Brady CJ, Harrison AJ, Flanagan EP, Haff GG, Comyns TM. A comparison of the isometric midthigh pull and isometric squat: Intraday reliability, usefulness, and the magnitude of difference between tests. Int J Sport Physiol. 2018;13(7):844-52. https://doi.org/10.1123/ijspp.2017-0480.

4. Hughes S, Chapman DW, Haff GG, Nimphius S. The use of a functional test battery as a non-invasive method of fatigue assessment. PLOS ONE. 2019; 14(2):e0212870. https://doi.org/10.1371/journal.pone.0212870.

5. Thorborg K, Branci S, Nielsen MP, Tang L, Nielsen MB, Hölmich P. Eccentric and isometric hip adduction strength in male soccer players with and without adductor-related groin pain: An assessor-blinded comparison. Orthop J Sports Med. 2014. https://doi.org/10.1177/2325967114521778.

6. Suzuki H, Omori G, Uematsu D, Nishino K, Endo N. The influence of hip strength on knee kinematics during a single-legged medial drop landing among competitive collegiate basketball players. Int J Sports Phys Ther. 2015;10(5):592-601.

7. Khayambashi K, Ghoddosi N, Straub RK, Powers CM. Hip muscle strength predicts noncontact anterior cruciate ligament injury in male and female athletes: a prospective study. Am J Sports Med. 2016;44(2):355-61. https:// doi.org/10.1177/0363546515616237.

8. Nimphius S, McBride JM, Rice PE, Goodman-Capps CL, Capps CR. Comparison of quadriceps and hamstring muscle activity during an isometric squat between strength-matched men and women. J Sports Sci Med. 2019;18(1):101-8.

9. Fortington LV, Finch CF. Priorities for injury prevention in women's Australian football: a compilation of national data from different sources. BMJ Open Sport Exerc Med. 2016;2(1):e000101. https://doi.org/10.1136/ bmisem-2015-000101.

10. Ryan S, Kempton T, Pacecca E, Coutts AJ. Measurement properties of an adductor strength-assessment system in professional Australian footballers. Int J Sport Physiol. 2019;14(2):256-9. https://doi.org/10.1123/ijspp.2018-0264.

11. Currell $K$, Jeukendrup AE. Validity, reliability and sensitivity of measures of sporting performance. Sports Med. 2008;38(4):297-316. https://doi.org/10. 2165/00007256-200838040-00003

12. Buchheit M, Morgan W, Wallace J, Bode M, Poulos N. Monitoring postmatch lower-limb recovery in elite Australian Rules Football using a groin squeeze strength test. Sport Perf Sci Rep. 2017;7:1-3.

13. Malliaras P, Hogan A, Nawrocki A, Crossley K, Schache A. Hip flexibility and strength measures: reliability and association with athletic groin pain. $\mathrm{Br}$ J Sports Med. 2009;43(10):739-44. https://doi.org/10.1136/bjsm.2008.055749.

\section{Publisher's Note}

Springer Nature remains neutral with regard to jurisdictional claims in published maps and institutional affiliations.

\section{Submit your manuscript to a SpringerOpen ${ }^{\circ}$ journal and benefit from:}

- Convenient online submission

- Rigorous peer review

- Open access: articles freely available online

High visibility within the field

- Retaining the copyright to your article

Submit your next manuscript at $\boldsymbol{\nabla}$ springeropen.com 